\title{
HOMENAGEM A ANTONIO MARIA DA SILVEIRA*
}

\author{
Carlos Lagrota Lopes ${ }^{* *}$
}

\section{Fabio N. P. de Freitas ${ }^{* * *}$}

Conhecemos Antonio em 1990, quando, retornando do pós-doutorado em Cambridge, assumiu o curso de Técnicas de Pesquisa em Economia no terceiro ano do curso de graduação em Economia da Universidade Federal do Rio de Janeiro (UFRJ). Não podíamos imaginar que aquele senhor magro e sorridente planejava uma revolução para nós. Em poucos meses estávamos discutindo filosofia econômica pelos corredores da faculdade, daí seguindo grupos de estudos, cursos na pós-graduação e trabalhos acadêmicos sobre o tema. Aprendemos a olhar a economia em uma perspectiva pluralista, buscando compreender a relação entre teorias formuladas no nível abstrato e o conhecimento aplicado à realidade. Esta nota é um tributo ao professor Antonio Maria da Silveira, que em seu persistente trabalho revolucionário (no melhor sentido de Thomas Kuhn) ajudou a formar várias gerações de economistas; e ao amigo Antonio que, com sua inteligência, bom humor e profundo senso de justiça, foi um exemplo para todos que com ele conviveram. ${ }^{1}$

Nascido em Ponte Nova, Minas Gerais, desde a infância Antonio Maria mostrou vocação para o magistério, algo que para ele se tornou evidente nas aulas particulares de matemática ministradas desde os 13 anos de idade. O gosto pela matemática o levou à graduação em Engenharia (Mecânica e Elétrica) na Universidade Federal de Minas Gerais (UFMG), onde se formou em 1963. O desejo de entender a sociedade, já acalentado ao longo da graduação, o trouxe para o campo das Ciências Sociais. A Administração foi

\footnotetext{
* Gostaríamos de agradecer os comentários e sugestões de José Antônio Pereira da Silva, João Luís Pondé, Antônio Henrique Silveira, Carlos Frederico Leão Rocha e Sonia Maria Pinheiro da Silveira a versões preliminares deste trabalho. Os eventuais erros e omissões presentes no trabalho são de inteira responsabilidade dos autores.

** Economista do BNDES.

*** Professor adjunto do IE-UFRJ.
} 
sua porta de entrada. Em 1964, Antonio ingressou no Instituto Tecnológico da Aeronáutica (ITA) como auxiliar de ensino na divisão de Engenharia Mecânica - opção produção - , atuando em disciplinas na área de Administração (e.g., Análise de Investimento). Em 1966, partiu para a pósgraduação nos Estados Unidos, na GSIA (Graduate School of Industrial Administration) da Universidade de Carnegie-Mellon. Nessa instituição, fixou inicialmente sua pesquisa no tema da análise de investimentos sob condições inflacionárias, dando continuidade a um trabalho que vinha desenvolvendo no ITA. Rapidamente seu interesse voltou-se para a análise do processo inflacionário, o que acabou por conduzi-lo ao campo da ciência econômica. Na GSIA, Antonio obteve o mestrado em Administração (em 1969) e o doutorado em Economia (em 1971). Retornando ao Brasil, em 1971, permaneceu no ITA até 1974. Nesse ano, convidado a integrar o quadro de professores da Escola de Pós-graduação em Economia da Fundação Getulio Vargas no Rio de Janeiro (EPGE/FGV-RJ), iniciou um vínculo com essa instituição que seria mantido pelos próximos 18 anos. Antonio também foi professor no mestrado em Administração da Fundação João Pinheiro (FJP, de 1976 a 1983), na graduação em Economia da UFMG (de 1977 a 1987) e na graduação e pós-graduação em Economia da UFRJ (de 1987 a 1992 como professor adjunto e de 1993 a 1995 como professor titular). Foi professor visitante em várias instituições de ensino superior, cabendo um destaque para sua passagem pela Universidade Federal de Uberlândia (UFU), onde seu vínculo foi mais estreito e prolongado (de 2002 a 2004). No período entre 1988 e 1990, Antonio voltou ao exterior para fazer pós-doutorado na Universidade de Cambridge, Reino Unido, onde se tornou membro permanente do Clare Hall College.

Ao longo de sua carreira, Antonio atuou profissionalmente nas esferas pública e privada. Entre 1976 e 1982, assessorou instituições financeiras privadas (primeiro o Citibank e depois o banco Multiplic). Publicou as edições Multiplic (de 1980 a 1982), que contribuíram para a difusão do tema da filosofia econômica nas universidades brasileiras. ${ }^{2} \mathrm{Na}$ primeira metade da década de 1980, foi editor da Revista Brasileira de Economia (RBE), na qual procurou soerguer o mais tradicional periódico de economia no Brasil, promovendo a renovação de todo o seu corpo editorial. Na segunda metade da década de 1980, implantou uma assessoria em estratégia governamental ${ }^{3}$ 
para o governo do Estado de Minas Gerais (de 1985 a 1986) e foi assessor econômico da bancada estadual do PMDB mineiro (em 1987). Em 1991, atuou como assessor técnico do senado, dedicando-se às discussões acerca do projeto de lei proposto pelo senador Eduardo Suplicy referente à instituição do programa de renda mínima no Brasil. De 1996 a 1998, Antonio foi secretário-geral da Associação Nacional dos Centros de Pós-graduação em Economia (ANPEC), e durante 1999 foi coordenador da comissão de especialistas em ciências econômicas no âmbito da Sesu/MEC.

Os primeiros trabalhos publicados por Antonio foram extraídos de sua tese de doutorado "Estudos sobre moeda e taxas de juros no Brasil", ${ }^{4}$ orientada por Alan Meltzer, ${ }^{5}$ um dos maiores expoentes da escola monetarista. Publicou ainda vários trabalhos em economia monetária nessa linha ao longo da década de 1970, muitos deles coletados nas edições Multiplic. ${ }^{6}$ Dois outros temas, no entanto, passaram a ocupar cada vez mais espaço em sua agenda de pesquisa: as limitações envolvidas na aplicação da teoria econômica à realidade e a erradicação da pobreza. $\mathrm{O}$ primeiro o levaria à filosofia econômica e o segundo, à defesa pioneira dos programas de renda mínima.

Antonio gostava de contar que desistiu da econometria ao constatar, logo após o seu retorno ao Brasil, a falsificação de dados econômicos realizada pelo regime militar. Do questionamento metodológico passou para a filosofia econômica, buscando entender a relação entre a teoria econômica e sua aplicação prática. ${ }^{7} \mathrm{Na}$ primeira metade da década de 1980 , passou a publicar artigos acadêmicos com contribuições ao tema ${ }^{8}$ e escreveu o livro Filosofia e política econômica: o Brasil do autoritarismo (IPEA, 1987). Nesse livro a discussão de temas de filosofia econômica abre caminho para uma crítica mordaz à tecnocracia, cuja pretensão de objetividade "científica" na gestão da política econômica havia alcançado um apogeu durante o período da ditadura militar.

Em sua passagem por Cambridge, no final da década de 1980, dedicou-se ao estudo da literatura clássica em economia. Na História da análise econômica, de Schumpeter, busca o conceito de Vício Ricardiano - o hábito dos economistas de ignorarem os elementos não econômicos que afetam as questões de política econômica. Desenvolvendo esse conceito, propõe a Indeterminação de Senior, assim definida por seu autor: 
As proposições da economia pura, não importando a generalidade ou verdade que encerrem, não autorizam conclusões normativas, mas não podem ser ignoradas. A economia social positiva entrelaça teorias econômicas puras e todas as ciências sociais, mas com relevância variável. Conclusões normativas — sob a forma do que não pode ser feito - são deriváveis de proposições da economia social, mas são ainda qualificáveis pelas especificidades de cada caso. ${ }^{9}$

Remetendo ao economista Nassau Senior, em quem primeiro identificou essa preocupação, Antonio estabeleceu que a obtenção de conclusões normativas com base na economia pura gera uma indeterminação, pela omissão de informações necessárias para a solução de problemas aplicados. Atribuiu uma divisão de trabalho na ciência econômica entre: a teoria abstrata ou economia pura (e.g., a teoria do crescimento), em que os modelos são avaliados por sua lógica interna e elegância; as teorias aplicadas ou economia social (e.g., a teoria do desenvolvimento), que envolvem mais de um campo de conhecimento e uma maior preocupação com a aderência aos dados; e a arte da economia, em que os profissionais lidam com problemas específicos. Antonio considerou que ignorar essa divisão do trabalho geraria vários problemas (e.g., o vício empiricista), dentre os quais o Vício Ricardiano se destaca por suas conseqüências associadas à proposição e à execução de políticas econômicas.

Formular a Indeterminação de Senior foi muito importante para Antonio. Nesse processo, ele finalmente se reconciliou com a ciência econômica após a grande desilusão causada pela constatação de que os dados econômicos haviam sido falsificados em $1973 .{ }^{10}$ Devolvida a tranqüilidade há muito perdida, Antonio construiu um profícuo programa de pesquisa baseado nessa idéia. ${ }^{11}$ Esse programa envolveu vários alunos de graduação e pósgraduação, entre os quais se encontram, orgulhosamente, os dois autores desta nota.

Em paralelo ao seu envolvimento com a filosofia econômica, Antonio iniciou sua participação no debate sobre a erradicação da miséria. Em Silveira (1975), introduziu no Brasil a proposta de um programa de renda mínima que reduzisse a pobreza por meio da transferência de renda para as famílias pobres. ${ }^{12}$ Propôs ainda que o seignoirage fosse utilizado para o financiamento do programa. ${ }^{13}$ Durante anos defendeu tenazmente a implan- 
tação do programa de renda mínima em aulas, conferências e artigos. Em 1991, colaborou com o senador Eduardo Suplicy no Projeto de Lei que propunha o estabelecimento de um Programa de Renda Mínima no Brasil. Como assessor do Senado, participou das discussões com parlamentares, assim como do debate público sobre o tema. ${ }^{14}$ Argumentou a favor do princípio de que o programa deve ser universal, e não condicionado a contrapartidas por parte dos beneficiários. Em sua concepção, a renda mínima é um direito do cidadão, e não um instrumento para incentivar determinados comportamentos.

Aos que argumentavam que a renda mínima sem contrapartida desestimula o trabalho, Antonio retrucava, inspirado em Herbert Simon, ${ }^{15}$ que o ser humano possui aspirações crescentes. Dizia ainda que utilizar o modelo de homem econômico - segundo o qual o trabalho gera desutilidade e as preferências são dadas — para argumentar que a renda mínima leva ao ócio era um exemplo de Vício Ricardiano. Nessas ocasiões, o filósofo e o reformista social se uniam pela mesma causa. ${ }^{16}$ Em sua visão, o argumento estava baseado em um preconceito contra os mais pobres, já que diversas outras formas de transferir renda, dissociadas de esforço (a herança, por exemplo), são aceitas pela sociedade sem contestação.

Quando escreveu seu artigo pioneiro em meados da década de 1970, o programa de renda mínima era uma idéia ousada (quase utópica) em um país onde o crescimento econômico estava associado ao autoritarismo e à miséria de grande parte de sua população. Mas, como escreveu em seu memorial, o longo prazo é o horizonte correto do professor. Três décadas depois, existem programas de renda mínima em todas as esferas de governo, e o Bolsa Família consolidou-se como política social permanente. Além disso, o programa de Renda Básica de Cidadania foi proposto pelo senador Eduardo Suplicy em 2001 e aprovado pelo Congresso Nacional em 2003. Certamente, o persistente trabalho de Antonio Maria em muito contribuiu para esse resultado. ${ }^{17}$

Como professor, Antonio destacava-se pelo prazer que demonstrava no exercício do magistério e no relacionamento com seus alunos. Não se tratava de um professor convencional. Mineiro de nascimento e por disposição, Antonio falava em um tom tranqüilo, escutava muito e sabia usar o humor. Gostava das provas com questões desconcertantes, tal como no 
curso de Filosofia Econômica, em que pedia ao aluno que, utilizando a matéria estudada, formulasse e respondesse à sua própria pergunta! Em seu curso não havia o que decorar, nem uma versão oficial da matéria a ser devidamente repetida durante a prova: era preciso entender e, mais importante, ter a sua própria opinião. Nos cursos de pós-graduação e em seus grupos de estudo, incentivava nos debates que o aluno desenvolvesse sua própria interpretação e, se bem fundamentada, que fosse apresentada em artigo para publicação.

A preocupação com a formação de economistas capazes de pensar de maneira crítica e independente também estava presente em sua participação nos debates acerca do ensino e pesquisa em Economia no Brasil. Nesse âmbito, Antonio foi um ardoroso defensor do pluralismo teórico e metodológico, em particular no caso da Economia, em que convivem - às turras, é verdade - diferentes escolas de pensamento. Costumava dizer que não deixou de ser monetarista para passar a pertencer a uma outra corrente de pensamento. O "credo" monetarista foi trocado pela visão de que todas as escolas de pensamento encerram meias-verdades temporárias. ${ }^{18}$ Acima de tudo, Antonio defendeu e pregou a tolerância com as diferenças de idéias. Sempre se posicionou fortemente contra as visões excludentes que, freqüentemente, ganham ímpeto na comunidade acadêmica em Economia.

Foram essas idéias que nortearam sua atuação nos debates a respeito do currículo do curso de Economia, dos quais participou ativamente ao longo da década de 1990. ${ }^{19}$ Nesses debates, Antonio defendeu o espírito da Resolução no 11/1984, que regulava o currículo dos cursos de Economia desde 1985. Em particular, identificava-se com a perspectiva pluralista que fundamenta os princípios básicos subjacentes a essa resolução. Via com grande temor a difusão no Brasil de um padrão de ensino de Economia do tipo norte-americano. ${ }^{20}$ Antonio entendia que esse padrão de ensino estava predominantemente voltado para a formação de "cientistas normais" (no pior sentido que se pode dar ao conceito proposto por Thomas Kuhn). Resultariam desse processo economistas sem a devida consciência dos limites do conhecimento apreendido ao longo de sua formação, bem como economistas inoculados de uma visão excludente e intolerante em relação às diferentes visões dos processos econômicos. Esse problema seria agravado pela au- 
sência de conteúdos de Filosofia e Metodologia nos cursos de Economia que poderiam dotar os alunos de capacidade de reflexão crítica acerca do conhecimento que estavam adquirindo. Tais "cientistas econômicos normais" estariam sendo submetidos à mais sutil e eficiente - porém perversa - forma de dominação, aquela associada ao controle do pensar. ${ }^{21}$ Com base nesse diagnóstico, Antonio lutou para que o princípio do pluralismo fosse mantido nas novas diretrizes dos cursos de ciências econômicas, assim como defendeu a inclusão de conteúdos de Filosofia e Metodologia no currículo de Economia. Foi bem-sucedido nos dois casos.

Os mesmos princípios e idéias expostos acima pautaram a marcante passagem de Antonio pela secretaria geral da ANPEC. Quando nela chegou, estava em curso mais uma tentativa de implantação de um projeto acadêmico excludente a partir da ANPEC, em que era proposto, entre outras coisas, o desligamento de Centros de Pós-graduação em Economia segundo um critério de desempenho. Antonio reagiu, consolidando e aplicando o princípio de que a ANPEC tem o papel de promover o ensino de pós-graduação em Economia no Brasil, e não atuar como mais um órgão voltado para a fiscalização, certificação e avaliação nesse campo. Nesse sentido, Antonio apoiou a criação de encontros regionais (inicialmente, o ANPEC - Nordeste; - , posteriormente, o ANPEC - Sul), assim como ampliou o escopo e o alcance do encontro nacional. Além disso, na condição de secretário-geral, apoiou a criação da Sociedade de Economia Política (SEP), uma associação de economistas de escopo nacional alternativa à Sociedade Brasileira de Econometria (SBE). Todas essas iniciativas lograram êxito, ampliando a participação da comunidade acadêmica em Economia na esfera da pós-graduação. Ainda é cedo, contudo, para avaliarmos se o movimento de inclusão acadêmica, acalentado por Antonio, prevalecerá sobre os projetos excludentes que recorrentemente chegam às instâncias decisórias da ANPEC. ${ }^{22} \mathrm{~A}$ esperança de que este seja o caso reside no fato de que existem várias pessoas na comunidade que compartilham os princípios da tolerância e pluralismo defendidos com fervor por Antonio.

Economista, filósofo, reformista social, foram muitas as dimensões da carreira de Antonio Maria da Silveira. Em todas essas áreas foi um pensador instigante e um ativo participante do debate acadêmico e de políticas públi- 
cas. Era, acima de tudo, um grande professor, que inspirava seus alunos a serem tolerantes com as diferenças acadêmicas e ousados na formulação de políticas públicas. Para os amigos, Antonio deixa a saudade da conversa inteligente, dos "causos" bem-humorados (que acabavam relatados em seus contos $)^{23}$ e de sua imensa generosidade. E para as novas gerações de economistas ficam seus livros, artigos e o exemplo de uma vida dedicada à universidade e à promoção da justiça social.

\section{NOTAS}

1. Na elaboração da presente nota usamos várias informações contidas no memorial de Antonio Maria apresentado no concurso para professor titular da antiga Faculdade de Economia e Administração da Universidade Federal do Rio de Janeiro (FEA/UFRJ) em 1992.

2. Aliás, como relatado em seu memorial, foi justamente a possibilidade de ter o material didático de seus cursos traduzido e organizado nas edições Multiplic que o motivou a trocar o Citibank pelo Multiplic.

3. É perceptível aqui a influência do trabalho de Igor Ansoff sobre estratégia empresarial na concepção da assessoria. De fato, em seu memorial, Antonio revela ter sido influenciado por Ansoff, professor da GSIA, com o qual manteve contato durante sua permanência em Carnegie-Mellon. Tal influência perpassa vários de seus trabalhos, com destaque para Silveira (1994).

4. Silveira (1973a, 1973b e 1974). A tese também foi publicada em português, na íntegra, em Silveira (1982b).

5. Alan Meltzer influenciou fortemente Antonio. Ele foi responsável por Antonio ter trocado a Administração pela Economia, assim como pela sua conversão ao monetarismo. Mesmo após deixar de ser monetarista, Antonio manteve um profundo respeito por Meltzer. Isso certamente explica como foi possível para os dois manterem contato ao longo dos anos, a despeito das crescentes diferenças de opinião.

6. Cf. Silveira (1981 e 1982a).

7. É desse período de reflexão que surge a idéia de publicar as edições Multiplic no início dos anos 1980 com a tradução de vários textos clássicos em torno do tema de Filosofia Econômica.

8. Silveira (1984) é o mais importante deles.

9. O conceito foi originalmente proposto em Silveira (1991). A citação acima se encontra em Silveira (1999).

10. O período em Cambridge trouxe ainda uma outra felicidade para Antonio. Logo após a sua volta ao Brasil, em 1971, ele ficou bastante contrariado ao realizar que seria inviável manter uma vida acadêmica em padrão internacional no país. O retorno ao exterior permitiu que Antonio retomasse um ritmo de produção em padrão internacional, pro- 
porcionando-lhe grande satisfação. Nesse fértil período, além do artigo com a Indeterminação de Senior, Antonio escreveu dois outros artigos em que analisa criticamente a contribuição do Prêmio Nobel James Buchanan (cf., Silveira, 1996a e 1996b).

11. Para um balanço parcial do programa de pesquisa da Indeterminação de Senior realizado pelo próprio autor, veja Silveira (1999).

12. Antonio travou um primeiro contato com a idéia da renda mínima ainda no seu período de doutorado nos EUA. Como relatado em seu memorial, desde seu retorno ao Brasil, em 1971, o tema passou a ser objeto de suas aulas inaugurais.

13. Nesse sentido, veja Silveira (1977).

14. Sua atuação na discussão do projeto de renda mínima no Senado, assim como artigos que publicou na imprensa estão registrados em Suplicy (1992).

15. Herbert Simon exerceu grande influência sobre Antonio. A admiração pelo seu trabalho foi o principal motivo para que ele escolhesse fazer pós-graduação na GSIA, onde Simon era professor. As idéias de Simon estão presentes em vários de seus trabalhos desde a década de 1970. A admiração de Antonio por ele pode ser evidenciada pelo fato de que, quando foi convidado a colaborar com um trabalho para a série de artigos sobre Prêmios Nobel para o periódico Literatura Econômica, Simon foi o laureado escolhido (Silveira, 1983). Os dois mantiveram contato durante e após o período de pós-graduação de Antonio em Carnegie-Mellon.

16. Um exemplo da utilização de argumentos da Filosofia Econômica no debate sobre o programa de renda mínima encontra-se em Silveira (2002).

17. A esse respeito, fazemos referência à bela homenagem do senador Eduardo Suplicy, disponível no endereço $<$ www.ie.ufrj.br/aparte/pdfs/suplicy_1_.pdf $>$.

18. A esse respeito, confira Silveira (1994b).

19. Antonio participou direta e indiretamente desses debates. Atuou diretamente na condição de coordenador da Comissão de Especialistas em Ciências Econômicas no âmbito da Sesu/MEC e como relator de parecer a respeito das novas diretrizes curriculares dos cursos de Ciências Econômicas. Participou indiretamente discutindo o assunto em suas aulas, palestras e, principalmente, em seus trabalhos escritos (cf., Silveira, 1999b e 1996).

20. Nesse sentido, veja Silveira (2000 e 2003).

21. Nesse ponto, Antonio certamente faria um paralelo com a Vigésima quinta hora, de, Gheorghiu, O admirável mundo novo, de Huxley, a Revolução dos bichos e 1984, de Orwell, as utopias negativas que tanto apreciava.

22. Convém registrar a esse respeito que, logo após a morte de Antonio e no mesmo dia em que a ANPEC o homenageava, foi aprovada pelo conselho deliberativo dessa instituição decisão que prevê a possibilidade de exclusão de um centro participante por critério de desempenho acadêmico.

23. Reunidos em Silveira (2005). 


\section{REFERÊNCIAS BIBLIOGRÁFICAS}

SILVEIRA, A. M (2005) Os Economistas também Amam. Contos-ensaios econômico-filosóficoamorosos. São Paulo: Livraria Projetos Editoriais.

(2003) "A ciência econômica na Europa e nos Estados Unidos: o prêmio Nobel e suas vieses". Econômica, v. 5, n. 2, p. 197-220.

_ (2002) “A renda básica na previsão de Keynes”, Econômica, v. 4, n. 1, p. 117-136.

(2000) "A ciência econômica na Europa e nos Estados Unidos: pluralismo versus Monismo”. Análise Econômica, v. 18, n. 34, p. 7-29.

(1999b) “A indeterminação de senior e o currículo mínimo de economia”. Revista de Economia Política, v. 18, n. 1, p. 182-199.

(1999a) "Indeterminação de senior: perspectivas e realizações de um programa de pesquisa”. Revista de Economia, v. 25, n. 23, p. 159-183.

(1996c) “O espírito da resolução 84”. In: Elias L. A., R. Gonçalves e A. dos Santos Mineiro (org.), O ensino de Economia. Rio de Janeiro: Corecon/IERJ/Sindecon, v. 1, p. 139-146.

(1996b) "A perspectiva da escolha pública e a inclinação institucionalista de Knight". Revista Brasileira de Economia, v. 50, n. 1, p. 111-133.

- (1996a). "A sedição da escolha pública: variações sobre o tema de revoluções científicas". Revista de Economia Política, v. 15, n. 1, p. 37-56.

(1994b) “Teorias econômicas: a meia-verdade temporária. Revista Brasileira de Economia, v. 48, n. 2, p. 203-216.

_- (1994a) "Aplicabilidade de teorias. Microneoclássica e estratégia empresarial. Revista de Economia Política, v. 14, n. 2, p. 53-75.

— (1991) “A Indeterminação de senior”. Revista de Economia Política, v. 11, n. 4, p. 70-88.

- (1987) Filosofia e política econômica: o Brasil do autoritarismo. Rio de Janeiro: IPEA.

__ (1984) “A Indeterminação de Morgenstern”. Revista Brasileira de Economia, v. 38, n. 4 , p. 357-383.

_ (1983) “Simon e satisfazimento". Literatura Econômica, v. 5, p. 587-606.

_ (org.) (1982b) “Estudos sobre moeda e taxas de juros no Brasil”. Rio de Janeiro: Edições Multiplic, v. 2, n. 9.

_ (org.) (1982a) “Modelos em moeda e redistribuição de renda”, Rio de Janeiro: Edições Multiplic, v. 2, n. 6.

—_ (org.) (1981) "Moeda e redistribuição de renda”, Rio de Janeiro: Edições Multiplic, v. 2, n. 2 .

(1977) “Erradicação da miséria e 'Laissez Faire’: o 'Seignoirage’ como fonte de recursos”. Revista Brasileira de Economia, v. 31, p. 77-95.

_ (1975) "Redistribuição de renda”. Revista Brasileira de Economia, v. 29, p. 3-15. 
(1974) "The money supply: the evidence from the brazilian economy". Kredit und Kapital, v. 3, p. 364-378.

(1973a) "Interest rate and rapid inflation: the evidence from the Brazilian economy". Journal of Money, Credit and Banking, v. 5, n. 3, p. 794-805.

(1973b) "The demand for money: the evidence from the Brazilian economy". Journal of Money, Credit and Banking, v. 5, n. 1, p. 113-140.

SUPLICY, E. (org.) (1992) Programa de Garantia de Renda Mínima. Brasília: Editora do Senado. 